Pak. j. sci. ind. res. Ser. A: phys. sci. 2015 58(1) 34-40

\title{
Manufacturing of Kevlar/Polyester Composite by Resin Transfer Moulding using Conventional and Microwave Heating
}

\author{
Iram Abdullah \\ Department of Polymer Engineering, National Textile University, Faisalabad, Pakistan
}

(received May 20, 2013; revised December 22, 2013; accepted January 07, 2014)

\begin{abstract}
Microwave heating was incorporated into the resin transfer moulding technique. Polytetrafluoroethylene (PTFE) mould was used to cure the composite panel. Through the use of microwave heating, the mechanical and physical properties of produced Kevlar fibre/polyester composites were compared to those manufactured by conventional resin transfer moulding. The flexural modulus and flexural strength of 6-ply conventionally cured composites was $45 \%$ and $9 \%$ higher than the flexural modulus and flexural strength of 6-ply microwaved cured composites, respectively. However, $19 \%$ increase in interlaminar shear strength (ILSS) and 2\% increase in compressive strength was observed in 6-ply microwave cured composites. This enhancement in ILSS and compressive strength is attributed to the better interfacial bonding of polyester resin with Kevlar fibres in microwaved cured composite, which was also confirmed via electron microscopy scanning. Furthermore, the microwave cured composite yielded maximum void contents $(3 \%)$.
\end{abstract}

Keywords: microwave curing, resin transfer moulding, polymer matrix composites, mechanical properties

\section{Introduction}

Resin transfer moulding (RTM) technique has been used more than 50 years for the manufacturing of fibrereinforced composite materials. Their high strength-toweight and stiffness-to weight ratio have led to their applications and uses in lots of major industries, and among these automotive and aerospace industry taking the larger part (Reia da Costa et al., 2012; Mouton et al., 2010; Harper, 2009; Potter, 1999). However, their high operational cost involved has restricted their wider use in industry and considerable efforts have been made to develope cost effective routes for curing of RTM composites.

RTM involves injecting a liquid thermosetting resin into a closed mould containing a dry fibre preform. Air and excess resin are purged through peripheral vents. The mould heating system raises the temperature of the mould body and the heat is transferred to the resin by conduction, initiating the exothermic reaction. Completion of the cure sequence is signalled by the cure at the injection gate. This is direct consequence of the thermal quench in that region and variation in chemical 'age' across the laminate (Johnson et al., 1998). Process developments involving zone heated moulds, phased initiator resin systems and pre-heating

E-mail: i_tayyab@hotmail.com the resin with microwave radiations have been used to compensate for thermal quench and have provided significant reductions in the cycle time (Agius et al., 2013; Johnson et al., 1998). Microwave radiation generates uniform heat within the material through conversion of electrostatic energy to thermal energy rather than heat transfer through conduction and convection (Thostenson and Chou, 1999). This made it attractive to be used for curing composites. Several attempts have been made to use microwave radiation for the curing of epoxy resin (Varaporn and Kaew, 2005; Zhou, et al., 2003; Boey and Yap, 2001; Fu and Hawley, 2000; Bai et al., 1995; Wei et al., 1993; Marand et al., 1992; Majovic and Wijaya, 1990a) and epoxy composites (Chaowasakoo and Sombatsompop, 2007; Rao et al., 2006; Varaporn and Dumrong, 2006; Nightingale and Day, 2002; Yue and Looi, 1995). It offers several advantages such as rapid, volumetric curing, energy saving, reduced processing time and improved processing control (Yusoff et al., 2007; Davies et al., 2007; Zhou et al., 2003; Ku et al., 2002; Bykov et al., 2001; Mijovic and Wijaya, 1990b). However, very little research work is available in which microwave radiation is used for curing RTM composites and it has not been fully exploited. Previously microwave radiation has been used for the curing of carbon/epoxy composite and it had substantially reduced the cure cycle time, 
energy requirements and operational costs. Furthermore, the stronger adhesion at the interface improved the stress transfer between the carbon fibre and the epoxy matrix (Papargyris et al., 2008). Consequently, the interlaminar shear strength for the microwave cured composite was improved. Microwave curing also forms a different molecular structure of polymer as compared with the conventional curing.

The aim of the present work is to incorporate microwave heating into the resin transfer moulding technique and to compare the overall physical and mechanical properties of the fabricated Kevlar/polyester composites with those obtained by conventional thermal resin transfer moulding. This is an attempt to assess if microwave radiation is also as efficient and feasible power source for curing Kevlar/polyester composite as it proved to be effective for the curing of carbon/epoxy composite.

\section{Materials and Methods}

The resin system used in this study was Norpol 420100, supplied by Rachold Chemicals. This resin system contains $75 \%$ polyester resin and $25 \%$ styrene with no added accelerator. Benzoyl peroxide obtained from Aldrich was used as $1 \%$ by the weight of resin as an initiator. Unidirectional high modulus aramid fibre roving UT-A 300/500P supplied by Heinsco, was used as reinforced material.

Resin transfer moulding (RTM) processing. Conventional thermal RTM processing. Conventional thermal RTM processing was based on the Hypaject 3/6 Mark II RTM injection system (Plastech) as illustrated systematically in Fig. 1. The system comprising of an inlet valve, a heated homogeniser, a pneumatic valve, a metal

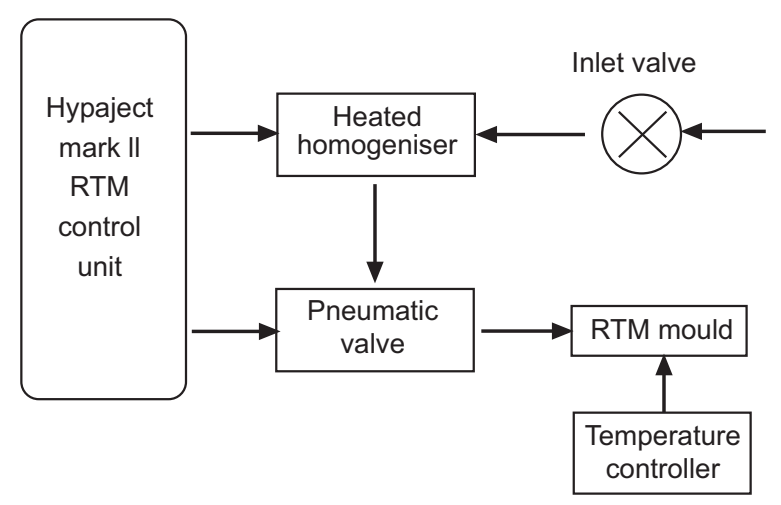

Fig. 1. Schematic diagram of conventional thermal RTM processing (black arrows indicate resin flow, grey arrows indicate process control). mould with 8 electric-cartridge heaters giving a total power output of $2 \mathrm{KW}$, two K-type thermocouples and two PID temperature controllers. Prior to the curing process, the metal mould was coated with Frekote 44$\mathrm{NC}$ release agent. The fibres were then placed inside the mould cavity $(200 \times 300 \times 3 \mathrm{~mm}$ dimensions $)$ and the mould was inclined at $45^{\circ}$ from horizontal in a steel stand in order to minimise air entrapment during the injection.

The resin was drawn into the homogeniser through the inlet valve and left for 10-15 min under vacuum in order to remove any air bubbles created at initial resin-hardener mixing stage. The resin was then injected under low pressure $(0.3$ bar) into the pre-heated mould through the inlet valve. After completion of injection stage, the resin loaded mould was heated for $45 \mathrm{mins}$ at $120^{\circ} \mathrm{C}$. The cure kinetic study on Norpol 420-100 unsaturated polyester resin showed that $95 \%$ of resin cures at $120^{\circ} \mathrm{C}$ The temperature controller maintained the cure temperature. Through this technique the following composites were prepared:

1.5 ply Kevlar/polyester composite,

2.5 ply Kevlar/polyester composite with preheated mould at $50{ }^{\circ} \mathrm{C}$ for $30 \mathrm{~min}$,

3. 6 ply Kevlar/polyester composite with preheated mould at $50{ }^{\circ} \mathrm{C}$ for $30 \mathrm{~min}$,

Microwave RTM processing. In microwave RTM processing microwave radiation was employed in order to cure the composite. A polyethylene tetrafluoroethylene (PTFE) mould of cavity dimensions of $200 \times 200 \times 3 \mathrm{~mm}$ was used. Preparation of mould prior to resin injection involved applying Chemlease $\mathrm{C} 15$ sealer agent and PMR Chemlease release agent. The fibres were then placed inside the cavity and the mould was again inclined at $45^{\circ}$ from horizontal during resin injection, which was carried out using Hypaject RTM system.

The microwave RTM heating equipment comprises a network analyser (Hewlett Packard HP8720ET) used as the power source, a travelling wave tube amplifier, an isolator, a multimode microwave applicator (Brass cavity), a PTFE mould and 4 fluoroptic probs (Luxtron Corp) connected to Luxtron 790 fluoroptic thermometer. The microwave system set up is shown in Fig. 2.

A computer control system was employed to ensure uniform heating and maintaining a stable cure temperature. Temperature stability was achieved by adjusting the microwave power while uniformity of the electric field distribution within the applicator was provided by 


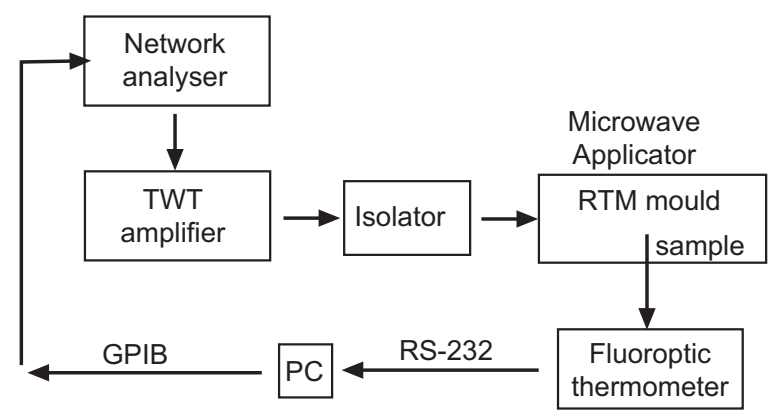

Fig. 2. Schematic digrarm of microwave RTM processing (Black arrows indicate microwave power flow, grey arrows indicate process control/temperature measurements).

varying the excitation frequency. Different excitation frequencies ranging from $6-8 \mathrm{GHz}$ were used for processing. It was observed that $7.339 \mathrm{GHz}$ was the best frequency for microwave to cure the polyester/ Kevlar composite with less noise ratio and $5 \mathrm{~W}$ power was reflected back to the amplifier.

Microwave power $(180 \mathrm{~W})$ and frequency $(7.339 \mathrm{GHz})$ was adjusted via a general purpose interface bus (GPIB) connection between the computer and the NA to raise the temperature of the mould from $27{ }^{\circ} \mathrm{C}$ to $120^{\circ} \mathrm{C}$ in $60 \mathrm{~min}$. The computer control system was designed in such a way that the NA would continuously step through the excitation frequencies, while simultaneously regulating the microwave power in order to maintain the $120^{\circ} \mathrm{C}$ cure temperature for $45 \mathrm{mins}$. The sample temperature was constantly monitored by the computer $v i a$ a serial connection with the fluoroptic thermometer. A typical 6-ply Kevlar/polyester microwave cured composite was prepared through this technique.

Mechanical testing. Differential scanning calorimetry (DSC). Differential scanning calorimetric studies were carried out on a TA instrument MDSC 2920 to ensure that the fabricated composite panels were fully cured. Small size samples $(10 \mathrm{mg})$ were heated from 0 to $300{ }^{\circ} \mathrm{C}$ at $20^{\circ} \mathrm{C} / \mathrm{min}$ in an inert nitrogen atmosphere. Samples were taken from different locations on each composite panel.

Flexural modulus. The flexural properties of composite samples were determined according to British Standard test method BS 2782: Part 3: Method 335A. The apparatus used was an Instron 1122 equipped with a three point bend jig. 6 samples $(60 \mathrm{~mm} \times 10 \mathrm{~mm})$ of each composite panel were tested and an average value was taken.
Interlaminar shear strength. Interlaminar shear testing of composite samples was conducted on an Instron 1122 with a load cell of $2 \mathrm{KN}$ according to British Standard method BS 2782: Part 3: Method 341A: 1977. 6 samples of each $(60 \mathrm{~mm} \times 10 \mathrm{~mm})$ composite panel were tested and average values were taken.

Compressive strength. $63 \mathrm{~mm}$ long/ $0.5 \mathrm{~mm}$ thick steel tabs were adhered on each composite sample of $140 \mathrm{~mm} / 6 \mathrm{~mm} / 3.3 \mathrm{~mm}$ dimension. The compressive test was carried out on an Instron 1185. The load cell was $50 \mathrm{KN}$ and the crosshead speed was $5 \mathrm{~mm} / \mathrm{min}$.

Quantitative microstructural analysis. Small fractions from the panels were cut and potted in epoxy resin. Each sample was first grinded using diamond grinder/polisher with metlap fluid dispenser and then polished for 10-20 mins using Mastertex cloth platen with an $\mathrm{AlSiO}_{2}$ abrasive of $1 \mathrm{~m}$ dimension.

Microstructural analysis was done using image analysis system. Images were acquired using a stero zoom microscope and a CCD black and white camera. On computer screen circumstance of the voids was manually traced out with a light pen. The computer programme 'Genias' was used to calculate the void contents. The following equation was used to calculate percentage void contents.

$\%$ age void content $=[$ High-lighted area $/$ total area of picture $] \times 100$

Scanning electron microscopy (SEM). Small fractions of fractured surfaces from mechanically tested samples were placed on metal stubs using double sided carbon tabs. The stubs with the fractured surfaces were then coated with a thin layer $(0.1 \mathrm{~mm})$ of gold using Edwards S150B sputter and examined for fibre-matrix interlaminar strength using Philips $\times$ L30 FEG SEM microscope.

\section{Resuts and Discussion}

The cured cycle employed for both conventional thermal and microwave RTM processing was $120^{\circ} \mathrm{C}$ for $45 \mathrm{~min}$. DSC results confirmed that the composites panels fabricated with these profiles were fully cured as shown in Table 1 . The quality of composite panel prepared through RTM processing depends upon the stiffness of the mould. The mould must resist all the loads; loads arise from the pressure required to compact the reinforcement and from the pressure of the resin injected into the mould. An additional pressure is also generated from the expansion of resin due to temperature changes. 
Table. 1. Mechanical and physical properties of Kevlar/polyester composites produced by conventional thermal and microwave RTM processing

\begin{tabular}{lllll}
\hline \hline Properties & $\begin{array}{l}\text { 5-Ply } \\
\text { conventional } \\
\text { thermal RTM }\end{array}$ & $\begin{array}{l}\text { 5-Ply preheated } \\
\text { conventional } \\
\text { thermal RTM }\end{array}$ & $\begin{array}{l}\text { 6-Ply preheated } \\
\text { conventional } \\
\text { thermal RTM }\end{array}$ & $\begin{array}{l}\text { 6-Ply } \\
\text { microwave } \\
\text { RTM }\end{array}$ \\
\hline Degree of cure (\%) & 99.6 & 99.5 & 99.8 & 99.5 \\
Void contents Vv (\%) & 0.49 & 0.45 & 0.47 & 3.4 \\
Flexural modulus (GPa) & $17.9 \pm 2.9$ & $17.3 \pm 1.9$ & $26.4 \pm 1.6$ & $14.4 \pm 4$ \\
Flexural strength (MPa) & $378 \pm 55$ & $404 \pm 28$ & $441 \pm 13$ & $401 \pm 24$ \\
ILSS (MPa) & $21.8 \pm 3.3$ & $22.3 \pm 3.3$ & $23.9 \pm 1.2$ & $28.5 \pm 4$ \\
Compressive strength (MPa) & $156.5 \pm 4.5$ & $161.4 \pm 5.7$ & $177.6 \pm 13$ & $181.6 \pm 23$ \\
\hline
\end{tabular}

This additional pressure in PTFE mould was delayed to zero during curing due to the lower stiffness of the mould. The deflection of mould from the centre caused shrinkage induced voidages (Fig. 3a-b), therefore, the void contents of microwave assisted RTM composite
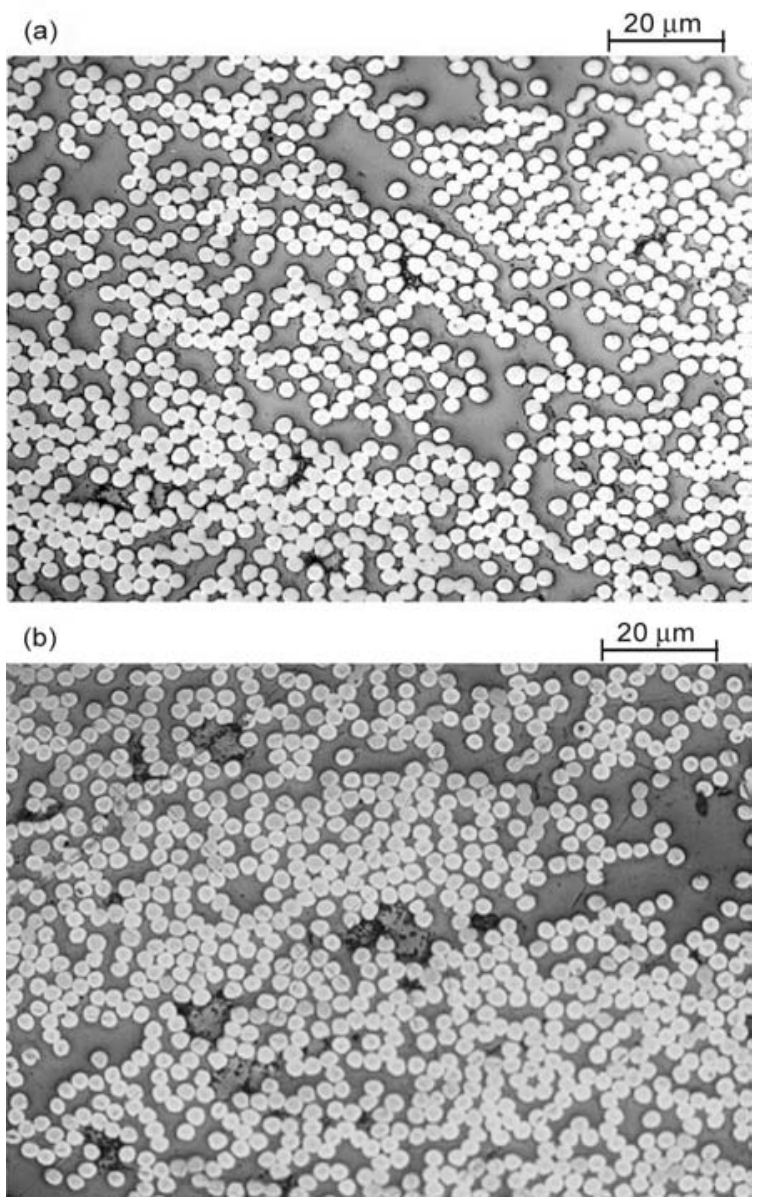

Fig. 3(a-b). Optical micrographs showing at same magnification voids in 6-Ply (a) conventional thermally cured RTM composite (b) microwave cured RTM composite. are much higher than the void contents of conventional RTM composite samples as shown in Table 1 . The surface quality of microwave assisted RTM composite is also poor as compared with the surface quality of conventional RTM composite panel as shown in Fig. (4a-b).

(a)

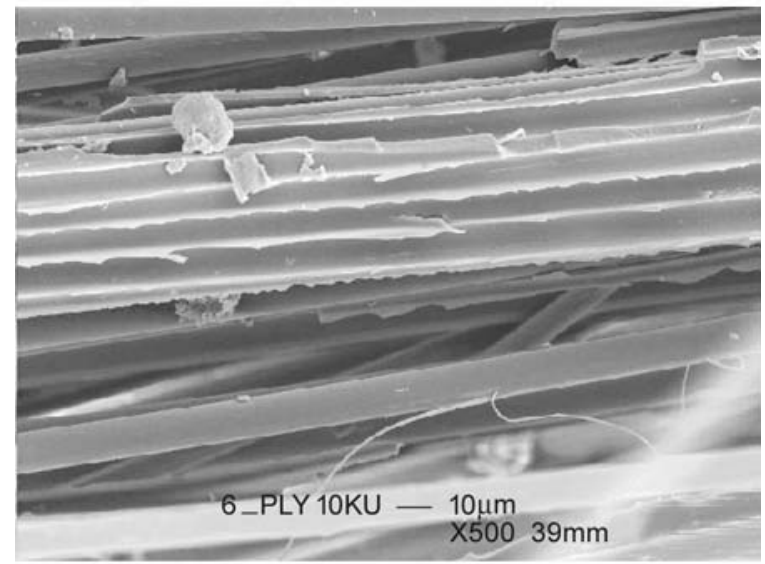

(b)

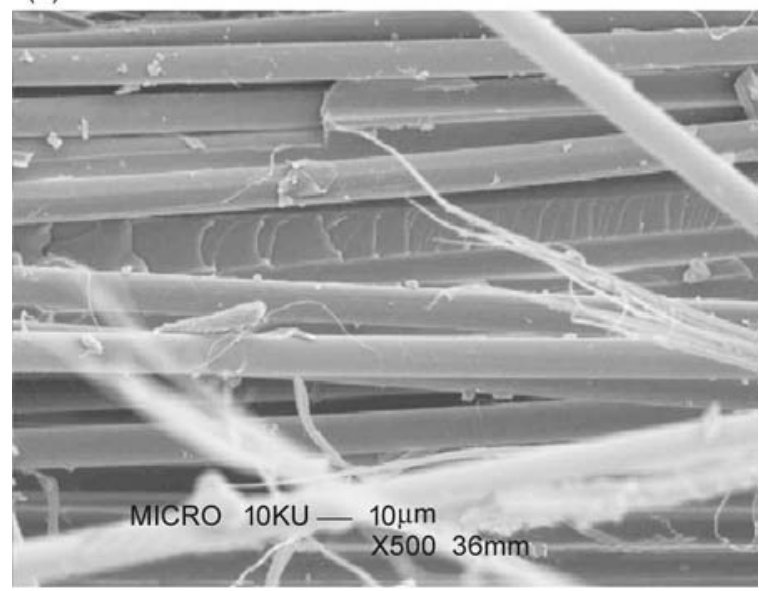

Fig. 4(a-b). (a) Conventional thermally cured RTM composite panel, (b) microwave cured RTM composite panel. 
The comparison of flexural mechanical properties of the manufactured composites (Table 1) shows that the flexural modulie of 6-ply microwave cured composite is lower than the 6-ply thermally cured composite. The flexural strength of microwave cured composite is slightly less than conventionally thermally cured composite. However, no distinctive improvement in the flexural modulie and strength of 5-ply conventional thermally cured composite can be concluded; both 5-ply composites exhibit the same flexural properties. The value of the interlaminar shear strength obtained for microwave cured composite is found to be slightly higher than those cured thermally, possibly signifying that the microwave curing improves the interfacial bonding between the Kevlar fibre reinforcement and polyester matrix. The fracture surfaces of composite samples subjected to interlaminar shear strength testing were also examined using scanning electron microscopy. Representative topographic features of both types of composites are shown in Fig. 5a-b. It can be seen from the fractured surfaces of the composites that in both conventionally cured and microwaved composites the fibres are pulled-out of the matrix system. However, in microwave cured composite resin traces are present on the fibre surfaces (Fig. 5b) as opposed to clean fibres present in thermally cured composite (Fig. 5a), which indicates that interfacial bonding in microwave cured composite may be slightly better than the interfacial bonding produced in conventionally cured composite. The smooth surface and inert chemical structure of Kevlar fibre prevents its interfacial bonding with most of the resins used in composites (Gu et al., 2012; Jia et al., 2011). The better compression strength value of microwave cured composites compared with the conventionally cured composites also indicated that either the microwave cured specimen exhibit better interface than conventionally cured specimen or the strength of the matrix in microwave cured specimen is high.

Generally, microwave heating is regarded as a volumetric heating technique in which the microwaves interact with the material and heat is generated directly as a result. Hence, heating is efficient because energy is deposited directly into the material and the effects of convection and conduction heat transfers are less significant than with some other heating techniques. In Kevlar/polyester composite; Kelvar is a low conductive fibre. The dielectric loss of composite is dominated by the dielectric properties of polyester matrix. Polyester molecules were heated directly inside the network structure; the induced (a)

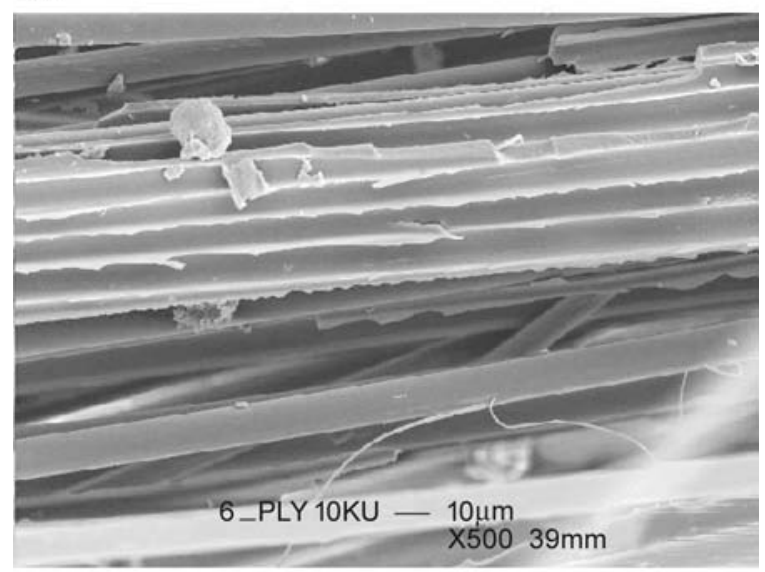

(b)

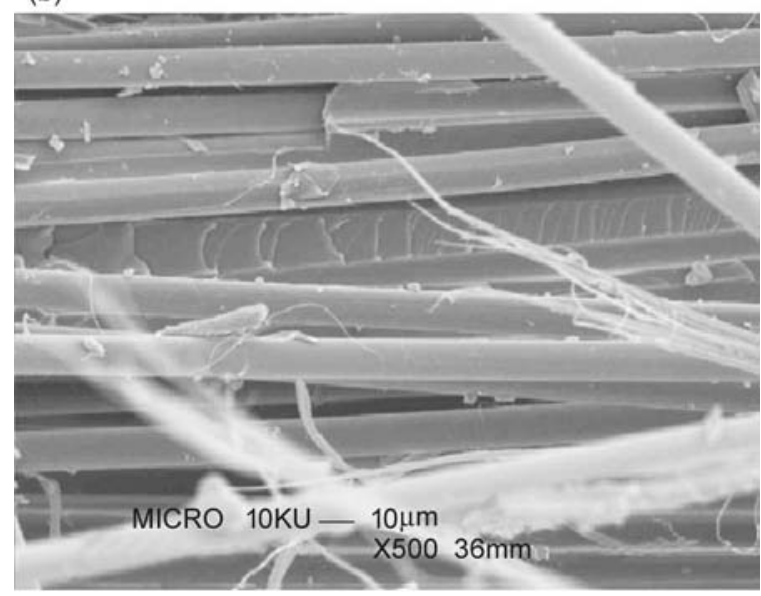

Fig. 5(a-b). SEM micrographs after interlaminar shear strength; (a) conventionally cured specimen (b) microwave cured specimen.

polymer polarisation along the applied electromagnetic field greatly increased the molecular mobility. This led to an increase in crosslinking inside the microgels. Kevlar fibres were heated in contact with polyester resin through conduction. The increased crosslinking created strong bonding at the fibre/matrix interface. The higher crosslinking is expected to improve the mechanical properties of microwave cured Kevlar/ polyester composites. The interlaminar shear strength (ILSS) increased by $19 \%$ and compressive strength was increased by $2 \%$, however, this increase was not profound as it comes in the range of experimental errors. No increase in flexural modulus and flexural strength is observed due to high void contents. The improvement in flexural strength and modulie can be achieved by selecting better mould material which must have dimensional stability to withstand the temperature and pressure cycle during processing. The reduction in void 
contents may further improve the mechanical properties of microwave cured composite.

\section{Conclusion}

In this study, the conventional resin transfer moulding (RTM) technique incorporated with microwave heating was presented. Composites were produced by both conven-tional thermal and microwave RTM processing in order to compare their physical and mechanical properties. The curing profile employed in conventional thermal and microwave RTM processing was 45 mins at $120^{\circ} \mathrm{C}$. DSC analysis of samples taken from different panel locations confirmed that the composites were fully cured, validating the uniformity of the microwave field inside the applicator. Mechanical testing showed lower values of flexural modulie and flexural strength for microwaved composite as compared with the conventional thermally cured composites. The interlaminar shear strength and compressive strength of the composites produced by microwave RTM processing was found to be higher than that of the thermally cured composites. This enhancement is suggested to be mainly attributed to the better interfacial bonding between the fibre surface and matrix. The microwave cured composites exhibited higher void content values than those cured conventionally. PTFE mould was too soft to remain in shape while curing of resin.

The results presented in this work underline the potential of microwave heating in improving composites processing and manufacturing. Despite the defects in mould used for microwave curing, the mechanical and physical properties of the microwave cured composites were found to be comparative and, in some cases, superior compared to the thermally cured composite. Further research is necessary in order to understand and explain the differences in the reaction mechanism between thermally and microwave cured composites. Optimisation of material and processing parameters is also required to achieve better mechanical properties, surface of composite panel and reduction in processing cost.

\section{Acknowledgement}

The Material Science Centre, UMIST, Manchester UK, is gratefully acknowledged for technical support.

\section{References}

Agius, S.L., Magniez, K.J.C., Fox, B.L. 2013. Cure behaviour and void development within rapidly cured out-of-autoclave composites. Composites Part B, 47: 230-237.
Bai, S.L., Djafari, V., Andreani, M., Francois, D. 1995. A comparative study of the mechanical behaviour of an epoxy resin cured by microwaves with one cured thermally. European Polymer Journal, 31: 875-884.

Boey, F.Y.C., Yap, B.H. 2001. Microwave curing of an epoxy-amine system: Effect of curing agent on the glass-transition temperature. Polymer Testing, 20: 837-845.

Bykov, Y.V., Rybakov, K.I., Semenov, V.E. 2001. High temperature microwave processing of materials. Journal of Physics D: Applied Physics, 34: R55-75.

Chaowasakoo, T., Sombatsompop, N. 2007 Mechanical and morphological properties of fly ash/epoxy composites using conventional thermal and microwave curing methods. Composite Science and Technology, 67: 2282-2291.

Davies, L.W., Day, R.J., Bond, D., Nesbitt, A., Ellis, J., Gardon, E. 2007. Effect of cure cycle heat transfer rates on the physical and mechanical properties of an epoxy matrix composite. Composite Science and Technology, 67: 1892-1899.

Fu, B., Hawley, M.C. 2000. Comparative study of continuous-power and pulsed-power microwave curing of epoxy resins. Polymer Engineering and Science, 40: 2133-2143.

Gu, R., Yua, J., Hua, C., Chena, L., Zhua, J., Hub, Z. 2012. Surface treatment of para-aramid fiber by Argon dielectric barrier discharge plasma at atmospheric pressure. Applied Surface Science, 258: 10168-10174.

Harper, A. 2009. RTM-past present and future. Reinforced Plastics, 11/12: 30-33.

Jia, C., Chena, P., Liua, W., Li, B., Wang, Q. 2011. Surface treatment of aramid fiber by air dielectric barrier discharge plasma at atmospheric pressure. Applied Surface Science, 257: 4165-4170.

Johnson, M.S., Rudd, C.D., Hill, D.J. 1998. Microwave assisted resin transfer moulding. Composites Part A: Applied Sciences and Manufacturing, 29A: 71-86.

Ku, H.S., Siores, E., Taube, A., Ball, J.A.R. 2002. Productivity improvement through the use of industrial microwave technologies. Computer and Industrial Engineering, 42: 281-290.

Marand, E., Baker, K.R., Graybeal, J.D. 1992. Comparison of reaction mechanisms of epoxy resins undergoing thermal and microwave cure from in Situ measurements of microwave dielectric properties and infrared spectroscopy. Macromolecules, 25: 2243-2252. 
Mijovic, J., Wijaya, J., 1990a. Comparative calorimetric study of epoxy cure by microwave vs thermal energy. Macromolecules, 23: 3671-3674.

Mijovic, J., Wijaya, J. 1990b. Review of cure of polymers and composites by microwave energy. Polymer Composite, 11: 184-191.

Mouton, S., Teissandier, D., Sébastian, P., Nadeau, J.P. 2010. Manufacturing requirements in design: The RTM process in aeronautics. Composites: Part A, 41: $125-130$.

Nightingale, C., Day, R.J. 2002. Flexural and interlaminar shear strength properties of carbon fibre-epoxy composites cured thermally and with microwave radiation. Composites Part A: Applied Sciences and Manufacturing, 33: 1021-1030.

Papargyris, D.A., Day, R.J., Nesbitt, A., Bakavos, D. 2008. Comparison of the mechanical and physical properties of a carbon fibre epoxy composite manufactured by the resin transfer moulding using conventional and microwave heating. Composites Science and Technology, 68: 1854-1861.

Potter, K.D. 1999. The early history of resin transfer moulding process for aerospace applications. Composites Part A: Applied Sciences and Manufacturing, 30A: 619-621.

Reia da Costa, E.F., Skordos, A.A., Partridge, I.K., Rezai, A. 2012. RTM processing and electrical performance of carbon nanotube modified epoxy/fibre composites. Composites Part A, Applied Science and Manufacturing, 43: 593-602.

Rao, R., Rao, S., Sridhara, B. 2006. Studies on tensile and interlaminar shear strength properties of thermally cured and microwave cured glass/epoxy composites. Journal of Reinforced Plastics Composites, 25: 783-795

Thostenson, E.T., Chou, T-W. 1999. Microwave processing: Fundamentals and applications. Composites Part A: Applied Sciences and Manufacturing, 30: 1055-1071.

Varaporn, T., Dumrong, J. 2006. Comparison between microwave and thermal curing of glass fiber-epoxy composites: Effect of microwave heating cycle on mechanical properties. Journal of Applied Polymer Science, 102: 1059-1070.

Varaporn, T., Kaew, S.T. 2005. Comparison of microwave and thermal cure of epoxy-anhydride resins: Mechanical properties and dynamic characteristics. Journal of Applied Polymer Science, 97: 1442-1461.

Wei, J., Hawley, M.C., Delong, J.D. 1993. Comparison of microwave and thermal cure of epoxy resins. Polymer Engineering and Sciences, 33: 1132-1140.

Yue, C.Y., Looi, H.C. 1995. Influence of thermal and microwave processing on the mechanical and interfacial properties of a glass/epoxy composite. Composites, 26: 767-773.

Yusoff, R., Aroua, M.K., Nesbitt, A., Day, R.J. 2007. Curing of polymeric composites using microwave resin transfer moulding (RTM). Journal of Engineering Science and Technology, 2: 151-163.

Zhou, J., Shi, C., Mei, B. 2003. Research on the technology and the mechanical properties of microwave processing of polymer. Journal of Material, Process and Technology, 137: 156-158. 